\title{
A PRÁTICA DA AGRICULTURA URBANA E O CULTIVO DE HORTÍCOLAS NO MUNICÍPIO DE SANTA MARIA-RS
}

Janete Webler Cancelier ${ }^{1}$

Cesar De David² Janete Facco ${ }^{3}$

Resumo: A agricultura desenvolvida para a produção de alimentos dentro de áreas urbanas/periurbanas vem redefinindo 0 uso dos espaços, proporcionando transformações nas relações sociais, ambientais e econômicas, modificando as paisagens e as dinâmicas de produção. $O$ crescimento da demanda por alimentos de qualidade tem possibilitado a permanência de atividades agrícolas nos espaços urbanos. O modo de vida pautado na maneira de produzir diferente passa a ser valorizado por desenvolver um sistema de produção particular e de especificidade local. Nesta perspectiva, ocorrem cultivos hortícolas em áreas periurbanas do município de Santa Maria (Rio Grande do Sul). A produção hortícola é considerada uma fonte de entrada de renda para as famílias, pois semanalmente os produtos são comercializados nas feiras, mercados e propriedades.

Palavras-chave: Agricultura urbana. Horticultura. Alimentação. Espaço. Agricultura Familiar.

\section{THE PRACTICE OF URBAN AGRICULTURE AND THE CULTIVATION OF VEGETABLES IN SANTA MARIA-RS}

Abstract: The development of the agriculture to the food production in the urban and periurban areas has been redefining the space use providing transformation in the social relation, environmental and economic modifying the landscape and the production dynamics. The demand increase for the quality food has made possible the agricultural activity permanence in the urban areas. The lifestyle pointed out in the way to produce different beginning to be appreciated for developing a private production system and local specificity. In this perspective, it can happen horticultural cultivation in periurban areas in Santa Maria city (Rio Grande do Sul). The horticultural production is considered an entrance of income to the families because of weekly the products are sold in supermarkets, fairs and in the houses.

Keywords: Urban agriculture. Horticultural. Food. Space. Family Agriculture.

\section{LA PRÁCTICA DE LA AGRICULTURA URBANA Y EL CULTIVO DE HORTALIZAS EN EL MUNICIPIO DE SANTA MARIA-RS}

Resumen: Agricultura desarrollada para la producción de alimentos dentro de las áreas urbanas/periurbanas ha redefinido el uso de los espacios, causando transformaciones en las relaciones sociales, ambientales y económicas, cambiando los paisajes y las dinámicas de producción. La creciente demanda de alimentos de calidad ha permitido que las actividades agrícolas permanezcan en los espacios

\footnotetext{
1 Universidade Federal de Santa Maria, Departamento de Geografia, Santa Maria, Brasil, janetewc@gmail.com, https://orcid.org/0000-0002-4850-5492

2 Universidade Federal de Santa Maria, Departamento de Geografia, Santa Maria, Brasil, cdedavid2009@gmail.com, https://orcid.org/0000-0003-0872-9181

3 Universidade Federal de Santa Catarina, Departamento de Geografia, Florianópolis, Brasil, janetefacco1@gmail.com, https://orcid.org/0000-0002-0843-9275
} 
urbanos. El modo de vida basado en la forma de producir diferente comienza a ser valorado por desarrollar un sistema de producción particular con especificidad local. Es en esta perspectiva que los cultivos hortícolas se dan en áreas periurbanas del municipio de Santa Maria (Rio Grande do Sul). La producción hortícola es una fuente de ingresos para las famílias porque los productos se comercializan semanalmente en ferias, mercados y propiedades.

Palabras clave: Agricultura urbana. Horticultura. Alimentación. Espacio. Agricultura familiar.

\section{Introdução}

Diferentes atividades relacionadas com a prática da agricultura vêm se desenvolvendo em distintos espaços urbanos/periurbanos. Estas atividades têm modificado as paisagens urbanas com da presença de cultivos que outrora se materializavam no espaço rural. A valorização do lugar em contraposição ao cenário internacional, vem possibilitando novas dinâmicas regionais, ao priorizar mercadorias de procedências fora do circuito das transformações padronizadas.

$\mathrm{O}$ crescimento da demanda por alimentos de qualidade tem possibilitado a permanência e a ampliação de cultivos agrícolas no espaço urbano. Espaços ociosos passam a ser utilizados com uma nova funcionalidade, a de produzir alimentos. Essas atividades, além de possibilitar entrada de renda para a as famílias, modificam as paisagens e as dinâmicas de produção.

A produção de alimentos saudáveis e produtos naturais passam a ficar mais evidentes. O modo de vida pautado na maneira de produzir alimentos de forma sustentável passa a ser reconhecido por desenvolver um sistema de produção particular e de especificidade local. Nesta perspectiva, ocorrem cultivos hortícolas em áreas periurbanas em vários municípios brasileiros, entre os quais está Santa Maria-RS. Compreendemos áreas periurbanas como "espaços de transição onde coexistem lógicas urbanas e rurais, criando espaços com atributos específicos" (PEREIRA, 2013, p.289). Não é a "localização urbana que distingue a agricultura urbana da agricultura rural, e sim o fato desta estar integrada e interagindo com o ecossistema urbano" (AQUINO; ASSIS, 2007, p. 3).

O presente artigo consiste em um exercício de identificação das atividades hortícolas desenvolvidas na área periurbana do município de Santa Maria-RS com o propósito de compreender os diferentes processos produtivos e a forma de organização dos agricultores, assim como a importância da horticultura para a reprodução social dos agricultores familiares que se dedicam a essas atividades. 
Nesse sentido, organizou-se a presente reflexão em itens: na introdução apresentamos a temática da pesquisa, na sequência, há uma explanação de natureza teórica/conceitual sobre espaço urbano e as atividades agrícolas, posteriormente, a área de pesquisa com a discussão dos resultados empíricos por fim, apresentam-se as considerações finais.

A pesquisa se caracteriza por ser de cunho qualitativo, apresenta uma abordagem interpretativa que se propõe a compreender a essência do fenômeno estudado a partir da pesquisa bibliográfica, de campo e análises. Os dados qualitativos foram obtidos por meio da sistematização dos questionamentos realizados entre os anos de 2018/2019, quando foram obtidas informações mais detalhadas, com três depoentes qualificados do município de Santa Maria-RS.

A amostragem se caracteriza por ser de cunho não probabilístico e selecionada pelo critério da acessibilidade, sendo composta por duas famílias de agricultores familiares que realizam cultivos hortícolas em áreas periurbanas e um representante público da esfera municipal, a partir do qual tornou-se possível identificar as áreas em que estes agricultores estão inseridos, bem como sua identificação. Também foram anotados no diário de campo as informações obtidas por meio de conversas informais com seis consumidores que se encontravam no espaço dos cultivos no período da realização da pesquisa de campo. O dialogo com sujeitos que de diferentes formas participam da atividade, seja como produtor, consumidor ou representante público, permite obter um panorama transversal da referida atividade.

A partir da metodologia utilizada, buscou-se levantar dados que permitissem compreender em quais bairros os agricultores hortícolas realizam seus cultivos, quantos são e como se organizam na área periurbana de Santa Maria-RS. Inicialmente um levantamento sobre as propriedades existentes, sequencialmente as pesquisas in loco com o levantamento de dados sobre as práticas adotadas, os produtos cultivados, a comercialização dos produtos, assim como os limites e potencialidades para a continuidade da atividade. As áreas pesquisas estão localizadas no bairro Juscelino Kubitschek. São 2 propriedades (A1 e A2), que, em 1,5 hectare, cultivam uma diversidade de produtos entre os quais se destacam: alface, rúcula, repolho, cenoura, quiabo, beterraba, pimentão, tomate, berinjela, pimenta biquinho, batata, temperos e chás.

Em ambas propriedades, o cultivo e a comercialização permitiu a permanência das famílias no local e sua reprodução social, apesar de não indicarem 
valores, o retorno financeiro é considerado positivo. Atualmente, a permanência destes cultivos decorre principalmente das características socioculturais dos consumidores, na busca por verduras e legumes de qualidade e origem local, o que inegavelmente propicia a valorização e o incentivo à continuidade dos mesmos.

\section{Localização da área de estudo}

O município de Santa Maria - RS, localizado na região central do Rio Grande do Sul (Figura 01), se caracteriza por ser a $5^{\text {a }}$ cidade mais populosa do estado e, isoladamente, a maior de sua região, possuindo no ano de 2018 uma população equivalente à 280.505 habitantes, dos quais $95 \%$ residem no espaço urbano.

Figura 01 - Localização do município de Santa Maria no Estado do Rio Grande do Sul

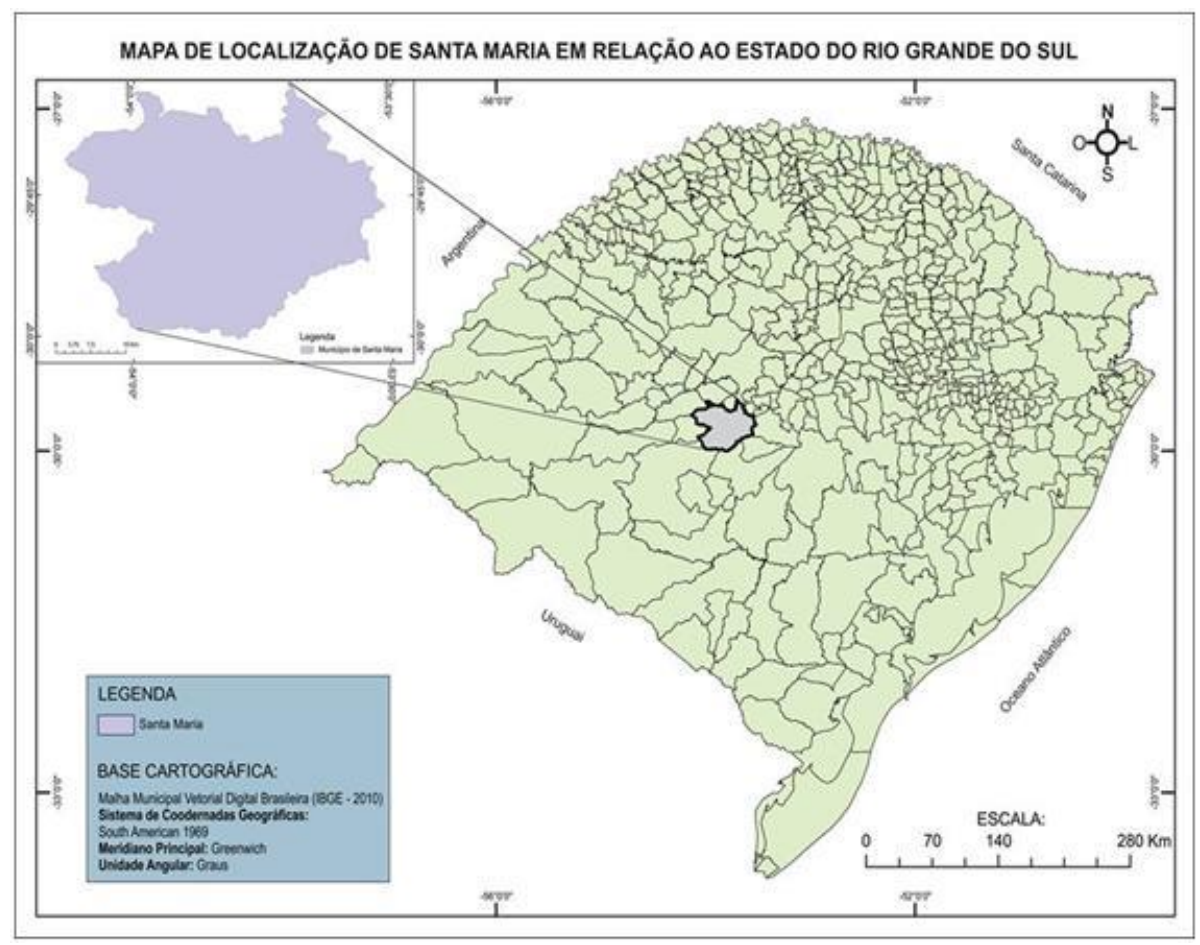

Fonte: Organizado pelos autores, 2019.

A taxa de crescimento anual da população, segundo estimativas do Instituto Brasileiro de Geografia e Estatística (IBGE, 2018), gira em torno de 0,69\%, o que demonstra a atratividade da mesma em relação aos demais municípios que compõem a região central do estado do Rio Grande do Sul. Ainda constitui-se no maior polo econômico da região central, destacando-se pelas atividades ligadas ao setor terciário, pelas instituições de ensino, assim como pela presença das bases militares. 
Sua configuração territorial está associada ao processo de ocupação e formação socioeconômica da região central do Rio Grande do Sul. Atualmente, em sua composição administrativa, o município esta composto por dez distritos, sendo nove rurais e um urbano, dentro do qual estão inseridos 41 bairros. Os bairros estão subdivididos em oito regiões administrativas, sendo elas: Leste, Centro Leste, Centro Urbano, Sul, Norte, Nordeste, Centro Oeste e Oeste.

Como área de abrangência da análise (lócus de pesquisa), elenca-se o bairro Juscelino Kubistchek (Figura 02), localizado na região administrativa oeste no município de Santa Maria - RS.

Figura 02 - Localização do bairro Juscelino Kubistchek

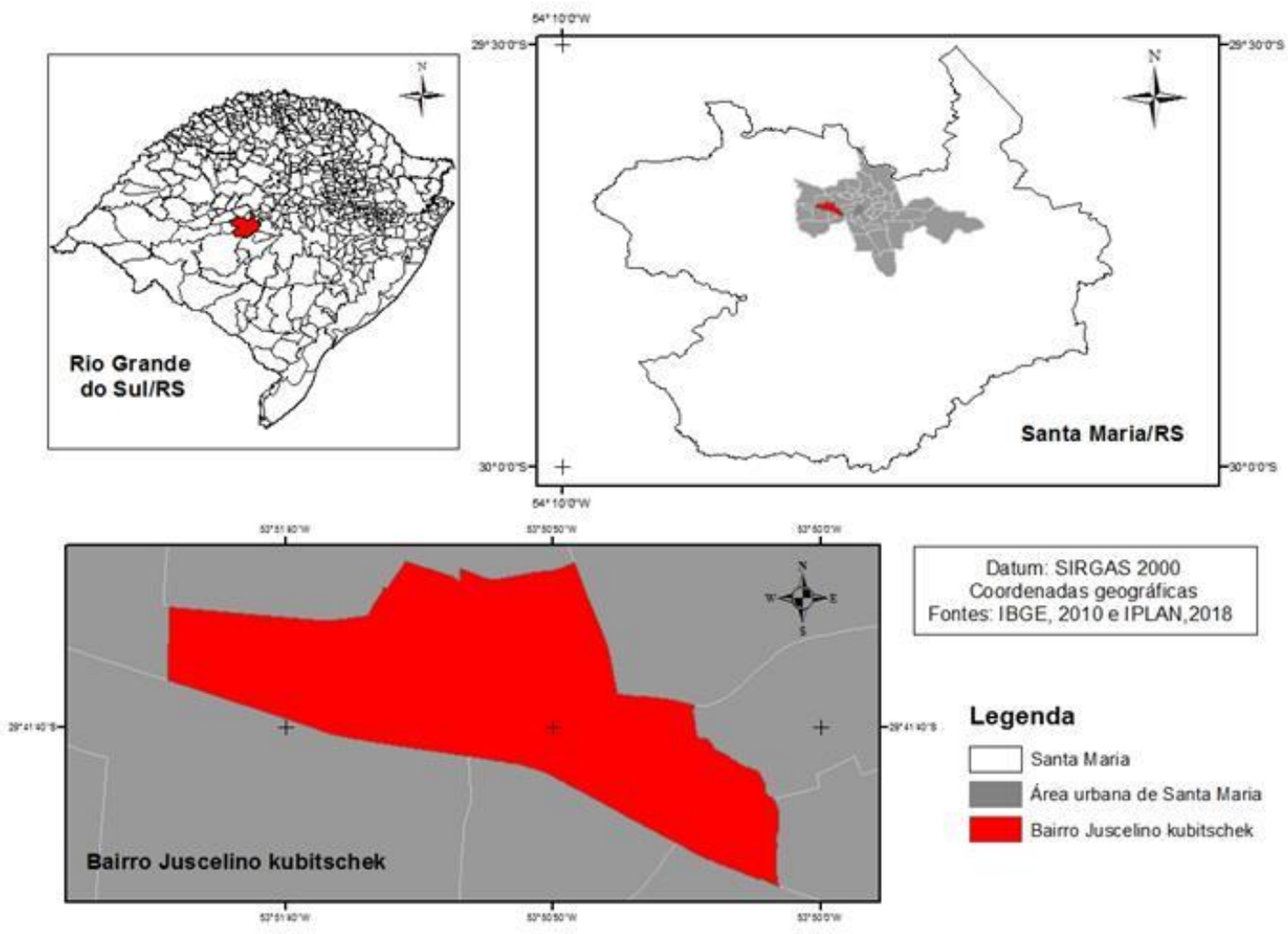

Fonte: Organizado por Janete Webler Cancelier, dados do IPLAN, 2019.

A região administrativa oeste segundo Bolfe (1997), se caracteriza como uma frente da expansão urbana, a qual se intensificou no município a partir de 1975, com a implantação do Distrito Industrial, onde foram estabelecidos conjuntos habitacionais que visavam fixar mão de obra para as indústrias, entre os quais está o bairro Juscelino Kubitschek.

Apesar desta área ser caracterizada pelo acelerado processo de urbanização e transformação das características naturais do território, ainda estão presentes neste espaço áreas de produção primária. Em Santa Maria, o crescimento dos 
bairros é predominantemente horizontal, a cidade se expande de forma espalhada, produzindo grandes vazios urbanos. A ampliação do perímetro urbano sobre áreas do espaço rural é mais uma consequência desse processo.

\section{Espaço urbano e as atividades agrícolas}

A sociedade contemporânea é marcada por expressivos processos de mudanças estruturais, entre os quais, o acelerado processo de ampliação das bases populacionais em áreas urbanas. $O$ crescimento, ocorre predominantemente nas periferias das cidades, espaços em que o valor da terra está mais acessível. A demanda de estrutura para o atendimento das necessidades básicas de moradia têm ampliado o perímetro urbano perante as áreas rurais, ocasionando o crescimento horizontal das cidades, novas dinâmicas e (re)configurações no uso do solo. Estes processos cristalizaram-se no primeiro momento nos grandes centros e posteriormente em cidades de porte médio, como é a cidade de Santa Maria-RS.

O elemento mais visível deste processo é a segregação espacial a que está submetida a população com menores condições financeiras, porém, "a expansão das cidades é acompanhada pela necessidade crescente de fornecer alimentos às famílias que nelas residem", (MELO, 2016, p. 5). A segregação espacial pode ser considerada como manifestação de pobreza, e, a pobreza urbana cabe a periferia e os lugares menos estruturados da cidade.

Santos; Silveira (2005) e Corrêa (2006), apontam que as cidades cumprem o papel de responder às necessidades da vida de relações a partir dos interesses dos agentes sociais e dos agentes territoriais, a demanda cumprida acaba sendo majoritariamente reclamada pelos agentes territoriais. As cidades são os pontos de superposição entre verticalidades e horizontalidades, elas oferecem meios para o consumo das famílias e das empresas, funcionam como entrepostos e fábricas, como depositárias e como produtoras de bens e serviços exigidas por elas próprias e por seu entorno (SANTOS e SILVEIRA, 2005), constituindo assim uma ponte entre o global e o local.

Em relação a urbanização brasileira Santos (2006), aponta que pouco se alterou até o final do século XIX, as taxas de crescimento da população urbana se ampliam exponencialmente a partir de 1940, como pode ser observado no Gráfico 01. 
Para compreender a urbanização brasileira faz-se necessário entender o processo histórico. No século $X X$ as fronteiras econômicas se ampliam, a globalização atua fortemente possibilitando a inserção de técnicas, informações e capitais em distintos espaços, em um processo desigual e combinado (SANTOS e SILVEIRA, 2005). Se ampliam as densidades técnicas com as tecnologias de comunicação e informação, e atividades com maior conteúdo capital, o que possibilita novas dinâmicas econômicas e sociais. Nesta conjuntura, as cidades, passam a desempenhar novos papeis e funções representados pelos capitais nacionais e internacionais.

Gráfico 01 - População urbana no Brasil

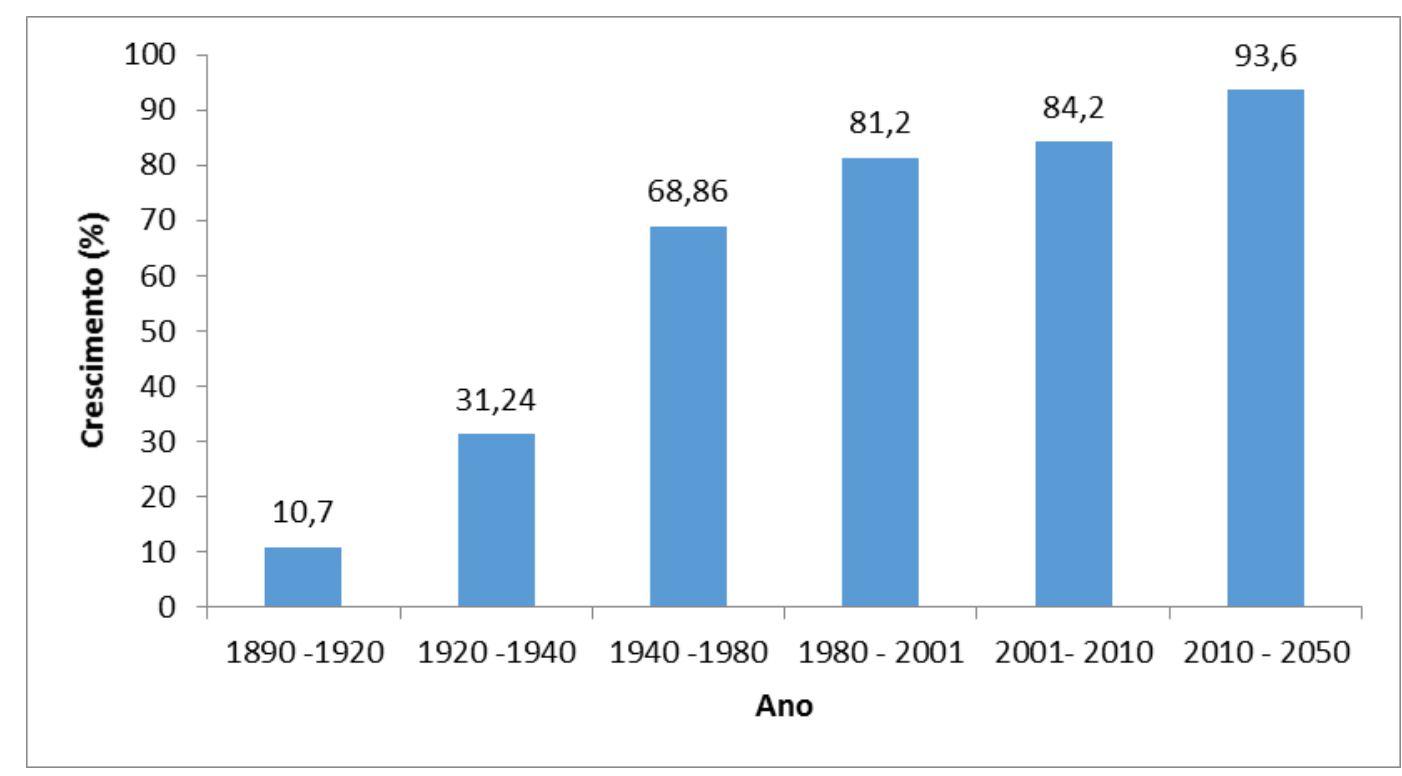

Fonte: Santos (2005), IBGE (2010) e ONU (2019). Organizado por Janete W. Cancelier (2019).

A partir deste contexto, intensifica-se o fenômeno da industrialização do país, investimentos públicos foram direcionados para a ampliação da base produtiva, o que afetou inegavelmente o espaço rural. A modernização agrícola, a substituição do homem pela máquina, a estrutura agrária concentrada e a busca por emprego e melhores condições de vida ocasionaram um crescente processo de êxodo rural.

A cidade passa a ser vista como espaço de referência, do moderno, das técnicas, do acesso a serviços, infraestrutura e do mercado de trabalho. A mudança da população da área rural para a área urbana acarretou significativas mudanças, entre as quais se destacam os hábitos de consumo e de alimentação da população. O contínuo deslocamento da população para as áreas urbanas exige maior disponibilidade de espaços para a construção das moradias e da infraestrutura, a qual acaba por vezes avançando perante espaços rurais. 
Neste contexto, concorda-se com Sposito (2018), que a produção do espaço urbano deve ser analisado, em diferentes escalas, tomando como base as diferenças e desigualdades socioespaciais em uma relação espaço-tempo. Ou seja, buscar a partir da análise temporal elementos para compreender na atualidade determinada realidade. Em relação a área de pesquisa, bairro Juscelino Kubitschek, o espaço urbano comporta além das atividades ligadas ao setor secundário e terciário, as do setor primário, com a agricultura.

A compreensão das distintas formas de uso do espaço urbano e a permanência das atividades agrícolas se coloca de forma complexa, na medida em que cada espaço possui características singulares. A esse respeito, Vilela e Moraes (2015, p.101), apontam que, o desafio amplia-se, principalmente, quando se tem em conta a multiplicidade de características da agricultura urbana e periurbana, em função da localização geográfica, do caráter de pertencimento do solo (público ou privado), das especificidades socioculturais de produtores envolvidos e da sua relação com o poder público em cada local.

O avanço da urbanização sobre áreas de produção primária é um fenômeno presente e atuante em distintos espaços, inclusive no município de Santa Maria-RS. Aquino; Assis (2007) apresentam outras cidades onde ocorre o mesmo: Porto Alegre-RS, Fortaleza-CE, Presidente Prudente-SP, Niterói-RJ, Florianópolis-SC e Campos dos Goitacazes-RJ. Alguns agricultores resistem, apesar do avanço incessante do setor imobiliário, permanecem cercados pela dinâmica do tempo rápido, da técnica, da vida urbana.

A pressão exercida pelos agentes mobilizadores do território, impõe dificuldades à continuidade das atividades. Contrariando as tendências, em pleno século XXI estão presentes em cidades de diferenciados portes, práticas de agricultura tanto em áreas urbanas quanto periurbanas. A prática da agricultura urbana e periurbana dá-se em um ambiente sociopolítico diferente do da agricultura rural e, ao mesmo tempo, em uma situação de complementaridade, porquanto não se trata de substituir a agricultura rural pela urbana e periurbana (VILELA; MORAES, 2015).

A prática da agricultura em áreas urbanas e sobretudo periurbanas vem se ampliando no decorrer dos anos, estando presentes: hortas caseiras, comunitárias com a utilização de áreas públicas para a produção de verduras e legumes, possibilitando 0 acesso de alimentos as comunidades carentes; particulares/comerciais cujo fim maior é a comercialização, as escolares, que 
permitem aos alunos o acesso as práticas de cultivo de alimentos, bem como de uma alimentação saudável, entre outros. O crescimento destas tendências tem levado pesquisadores e instituições a se interessar pelo tema, os quais buscam compreender a amplitude do fenômeno e seu papel como substrato espacial na alimentação da população urbana.

As atividades vinculadas a agricultura desenvolvidas em áreas urbana/periurbanas, geralmente desenvolvem-se com técnicas de manejo menos agressivas ao meio ambiente, caracterizadas pelo viés da agroecologia. A facilidade de acesso, a proximidade dos consumidores, a inserção do consumidor na área de cultivo, o qual muitas vezes pode colher o que pretende comprar, a qualidade do alimento, constituem-se como elementos positivos. A agricultura urbana tem a função de aumentar a disponibilidade de alimentos frescos, de boa qualidade nutricional sem, contudo, requerer grandes gastos com produção (OLIVEIRA, 2011).

As práticas da agricultura urbana e periurbana ocorrem em espaços onde há agricultura integra-se ao sistema econômico e ecológico urbano e ao mesmo tempo inter-relaciona- se com a agricultura rural (ADAM, 1999; MOUGEOT, 2000). Essa interação possibilita mudanças nas paisagens urbanas, as quais passam a ser resignificadas a partir dos novos usos dos espaços da cidade com atividades que anteriormente ocorriam prioritariamente em áreas rurais.

Ao realizar uma análise do espaço faz-se necessário entender os fenômenos em sua totalidade, ou seja, a materialidade é o resultado das relações sociais, dos sistemas naturais e da influência antrópica exercida sobre estes (Santos, 2006). Dessa forma, "o espaço é resultado da ação dos homens sobre o próprio espaço através dos objetos, naturais e artificiais no território" (Santos, 2008).

Cada espaço pode ter seu uso modificado ou resignificado a partir de ações diretas e indiretas como bem atesta Santos (2006). Partindo destas premissas constatou-se que no bairro Juscelino Kubitschek, estão presentes dois substratos espacial material agrário materializados em sua área urbana. Pode-se entender um substrato espacial material agrário materializado em uma área urbana enquanto o resultado da ação do homem sobre o território. Por sua vez, Souza (2013, p.74), destaca que o "substrato é portador de símbolos e mensagens, nos objetos geográficos da paisagem, que colaboram, para a socialização e a (de) formação de hábitos, costumes e mentalidades". 
A efetivação destes substratos e seus cultivos decorrem principalmente pelas especificidades socioculturais da população residente pela demanda por verduras/legumes e frutas e valorização do cultivo local.

Neste contexto, o modo de vida pautado na maneira de produzir diferente passa a ser valorizado por desenvolver um sistema de produção particular e de especificidade local, ganha espaço nos mercados e identifica o lugar, uma região e até mesmo um modo de único de vida e de produção. Dessa forma, o processo que globalizou a economia mundial, contraditoriamente, promove a valorização das diferenças, ao priorizar mercadorias de procedências fora do circuito das transformações padronizadas pela tecnologia em curso. A valorização do cultivo local, a produção de alimentos saudáveis e de produtos naturais passam a ficar mais evidentes, principalmente pela forma de produzir e se destacam no ambiente urbano.

Nesta perspectiva, estão os cultivos hortícolas em áreas periurbanas. Compreendemos áreas periurbanas como espaços de transição onde coexistem lógicas urbanas e rurais, criando espaços com atributos específicos, fragilidades e potencialidades próprias, resultantes das interações dos elementos urbanos e rurais, a transição se destaca do ponto de vista paisagístico, socioeconômico e ambiental (PEREIRA, 2013, p.292). A ampliação das práticas agrícolas nos espaços urbanos e a relação urbano-rural podem ser consideradas complementares (WANDERLEY, 2000).

O cultivo de hortícolas agrícolas é uma importante atividade desenvolvida para a alimentação das cidades. O crescimento da demanda por alimentos de qualidade, saudáveis, passa a ser um nicho do mercado que tem possibilitado a manutenção e a permanência de atividades agrícolas no espaço urbano, as quais cultivam alimentos para as demandas locais e, fomenta o desenvolvimento de uma agricultura sustentável, ou seja, espaços agrícolas urbanos que possuem um entendimento profundo da natureza, dos agroecossistemas.

As exigências ultrapassam a simples função daquilo que o espaço pode produzir e ficam centradas nas inúmeras demandas do mercado, modificando as paisagens e as dinâmicas de produção. "O espaço deve ser considerado como conjunto indissociável de que participam, de um lado, o arranjo de objetos geográficos, naturais e sociais, e, de outro, a vida que os preenche e os anima, ou seja, a sociedade em movimento" (SANTOS, 1997). Procurando entender como 
essas práticas de manifestam na área urbana/periurbana do município de Santa Maria apresenta-se na sequencia as áreas pesquisadas.

\section{As propriedades agrícolas pesquisadas}

Fizeram parte desta pesquisa duas propriedades que realizam cultivos hortícolas na área urbana do no município de Santa Maria- RS, denominadas neste estudo como A1 e A2. As unidades estão inseridas no bairro Juscelino Kubitschek desde os anos de 1970, cultivam uma diversidade de produtos entre os quais se destacam: alface (roxa/verde), cenoura, quiabo, beterraba, tomate, alho poró, rúcula, repolho, couve, brócolis, couve flor, pimentão, berinjela, pimenta biquinho, batata, temperos e chás. No período inicial cada propriedade cultivava em torno de 4 hectares, atualmente a área consiste em um hectare, para cada unidade. A diminuição da área destinada aos cultivos está diretamente relacionada à falta de mão de obra e ao envelhecimento dos gestores.

Os agricultores têm origem na mesma família, dois irmãos, via arrendamento de terras, na forma individual, começaram a plantar verduras e legumes, com o passar do tempo através do retorno econômico obtido com a atividade conseguiram comprar as terras que arrendavam, espaços estes que ainda cultivam.

Em ambas as unidades os clientes são consumidores diretos, destacando-se aqueles que já compravam anteriormente, a vizinhança, os feirantes do centro e donos de lanchonetes. Os agricultores já possuíam relações comerciais estabelecidas e diversificadas. Mas a propaganda realizada pelos próprios consumidores ampliou significativamente o número de consumidores que se dirigem semanalmente as propriedades.

A pesquisa de campo foi realizada em dois períodos distintos, um no verão e outro no inverno. No verão, observou-se um intenso movimento de consumidores na horta, passando 10 clientes na hora em que nos encontrávamos no espaço, os quais adquiriram em média, cada um, R\$15,00 em verduras/legumes. Segundo os proprietários esse movimento é constante. A esse respeito a agricultora relata "hoje é um dia calmo, em dia de movimento não consigo parar, principalmente nas primeiras horas da manhã e tem ainda as pessoas que encomendam por telefone, os donos de lancherias e trailers" (A1, Diário de Campo, 2019). Já no inverno esta dinâmica se altera, a maior parte dos consumidores se dirigem ao espaço entre sexta-feira e sábado. Donos de lanchonetes são clientes fixos, tanto no inverno quanto no verão. 
A produção de verduras é considerada uma fonte de renda importante para as famílias, justamente por possuir um valor agregado ao trabalho familiar e pelo não uso de agrotóxicos. Os produtos são diversificados com preço acessível, como pode ser observado na Tabela 01. Convém destacar que o tipo de produto cultivado e o valor mudam de acordo com as estações do ano, sendo maior a disponibilidade e a diversidade de produtos na primavera/verão.

Tabela 01 - Produtos $X$ Valor

\begin{tabular}{l|c}
\hline \multicolumn{1}{c|}{ Cultura } & Valor R\$ \\
\hline Alface crespa, lisa, roxa ( pé ) & $\mathrm{R} \$ 2,00$ \\
\hline Cenoura ( maço) & $\mathrm{R} \$ 4,00$ \\
\hline Tomate (Kg) & $\mathrm{R} \$ 4,00$ \\
\hline Pimentas (Kg) & $\mathrm{R} \$ 5,00$ \\
\hline Temperos ( maço) & $\mathrm{R} \$ 2,00$ \\
\hline Brócolis & $\mathrm{R} \$ 2,50$ \\
\hline Couve (maço) & $\mathrm{R} \$ 3,00$ \\
\hline Beringela (Kg) & $\mathrm{R} \$ 3,00$ \\
\hline
\end{tabular}

Fonte: Autores (2019).

Os espaços são visualizados enquanto "ilhas" de plantação de verduras, hortaliças, legumes e raízes em meio a um cenário de concreto, casas, serviços e prédios. Inicialmente as áreas estavam inseridas na zona rural, mas com a ampliação do perímetro urbano passam a ser consideradas urbanas. Como diversos outros elementos da cidade, a agricultura urbana e periurbana é fruto da ação humana e objeto de representações, sentidos e construções simbólicas (VILELA; MORAES, 2015). Considera-se as áreas de cultivo como substrato espacial material agrário dentro da área urbana, conforme Figura 03. 
Figura 03 - Substrato material agrário

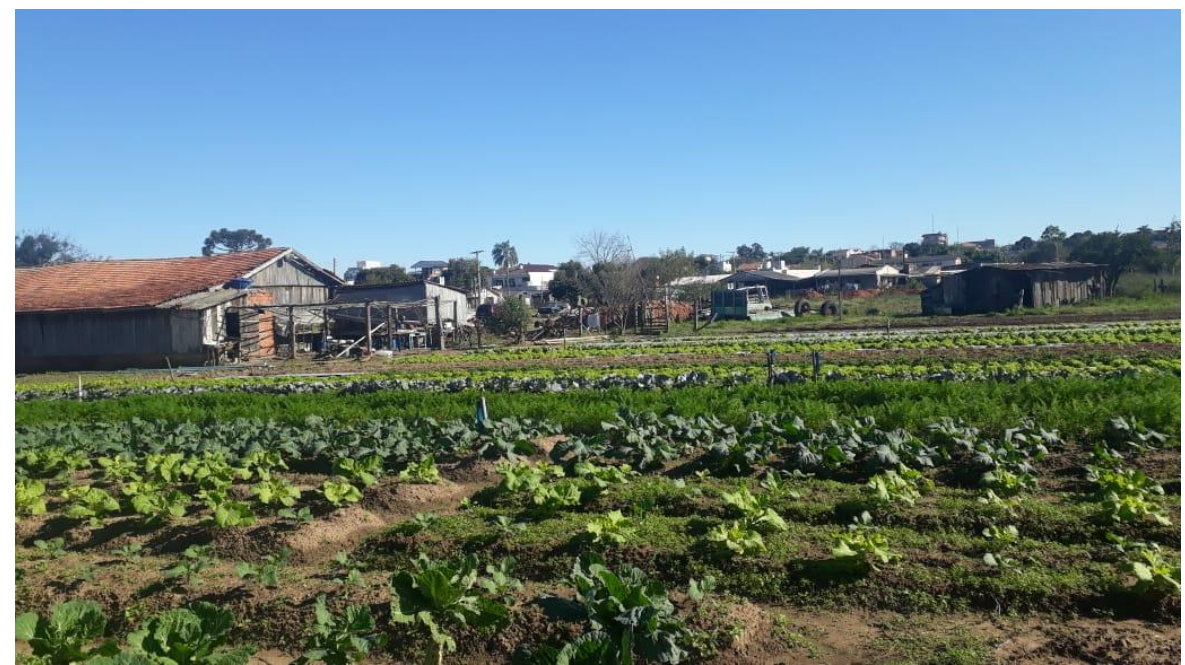

Fonte: Autores (2019).

O crescimento horizontal das cidades é um fenômeno presente e atuante em distintos espaços. A esse respeito Villaça (1998, p. 188), evidência que "estimuladas pelos interesses imobiliários, as elites urbanas estão constantemente produzindo novos bairros e deixando outros para trás", e nos "espaços próximos ao perímetro urbano das cidades, a agricultura periurbana tem sofrido pressões para continuidade das atividades devido a especulação imobiliária e valorização do espaço urbano" (GOES et al, 2018, p. 108). Bem como do posicionamento do poder público municipal, que através de suas ações vem legitimando os interesses imobiliários.

Esse processo é verificado na área de pesquisa, uma vez que os proprietários das unidades possuíam até o ano de 2018 o bloco de agricultores e pagavam o Imposto Territorial Rural - ITR. Apesar o imóvel estar localizado na área urbana, havia o entendimento de que para a cobrança dos tributos prevaleceria a destinação rural do imóvel, ou seja, sua função. Contudo, segundo os depoentes, no ano de 2019, ocorre uma alteração, a prefeitura municipal não identifica mais a área como um espaço agrário, passando a incidir sobre as mesmas o Imposto Predial Territorial Urbano - IPTU. O qual possui valor mais elevado em relação ao ITR.

Os agricultores já estão aposentados, mas evidenciam a insatisfação com a nova medida, haja vista, que amplia os custos, já que cada área possuem em torno de 2,5 hectares. A pressão exercida sobre os mesmos coloca em risco a continuidade da atividade, já que financeiramente é mais atrativo construir imóveis e alugar. 
Áreas como as pesquisadas melhoram a gestão sustentável do espaço urbano, incrementando o aumento de áreas verdes, cooperando para melhorar a paisagem, a qualidade do ambiente urbano e amenizando o microclima local (MELO, 2016). "A agricultura urbana e periurbana na atualidade é uma realidade presente em muitas áreas urbanas mundiais independentemente da escala de produção" (GOES et al, 2018, p. 110).

\section{As percepções dos agricultores e as estratégias adotadas}

As estratégias adotadas para o acesso ao mercado são diferenciadas. A unidade $\mathrm{A} 1$, até meados dos anos de 1980 comercializava com os quartéis presentes no município e na propriedade, não acessando diretamente feiras e mercados, posterior a este período toda comercialização ocorre somente na propriedade. $\mathrm{Na}$ unidade $\mathrm{A} 2$, até 1990 , toda a produção se destinava exclusivamente às demandas dos feirantes que possuíam suas bancas localizadas no centro da cidade de Santa Maria-RS, sendo responsabilidade da família levar os produtos até os locais de comercialização. A partir de 1991, as estratégias de comercialização foram alteradas e os clientes passaram a se dirigir até a área de cultivo, onde compram diretamente do produtor.

A inserção do cultivo na área urbana não dificultou a venda dos produtos, pelo contrário, ampliou, como bem atesta A2 "hoje o consumidor passou a se deslocar até nós, o acesso é bom, agora tudo asfaltado" (Diário de Campo, 2019). A1, relata que: "até 1980, todo dia encostava um caminhão aqui, levava tudo para o quartel, era muita produção, em 4,5 hectares produzia muito (Diário de Campo, 2019).

Ao relatar sobre as origens, ambos depoentes destacam que possuem uma relação direta com práticas da agricultura, "cresci plantando verduras com meu pai, o trabalho era todo feito pela família, um tempo difícil, meu pai só produzia em terra arrendada, não tinha como comprar..." (A1, Diário de Campo, 2019). Isso corrobora com VILELA; MORAES (2015, p. 102), quando afirmam que as cidades, no processo de urbanização nacional, guardam relações com o mundo rural, as quais se expressam tanto como realidades físicas, quanto materializadas em formas de vida e de mentalidade. È a resistência dos elementos do espaço rural resistindo ao espraiamento urbano, formando assim, novas paisagens com funções distintas. A partir da Figura 04 pode-se visualizar parte da área de cultivo do A1 e A2. 
Figura 04 - Área de cultivo (esquerda A2, direita A1)
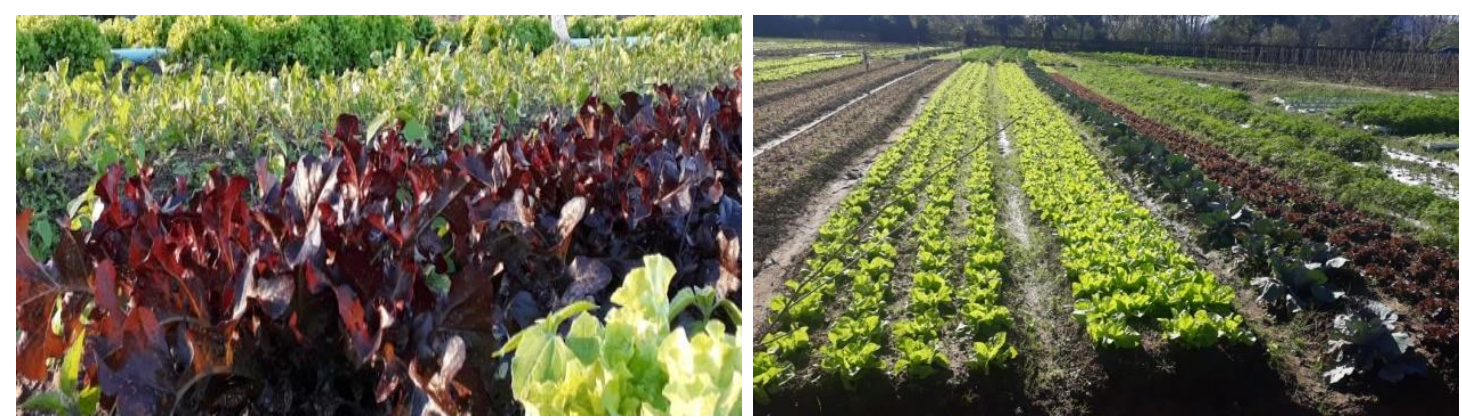

Fonte: Autores (2019).

Os depoentes relatam que as famílias sempre sobreviveram com a renda proveniente da comercialização da horta a partir do cultivo das verduras. Inclusive as propriedades assim como demais bens foram comprados com essa renda. Partindo disso, este "território-campo deve então, ser encarado do ponto de vista da valorização de uma herança específica, onde se mesclam elementos da cultura (determinados produtos, formas de produzir, saberes, etc) e da natureza (potencialidades naturais), em diálogo com outras formas culturais" (VILELA; MORAES, 2015 p. 104).

Em ambas as propriedades, inicialmente todo o trabalho era realizado pela família, o casal e dois filhos. Os filhos auxiliaram diretamente em todas as etapas do cultivo até a adolescência, período no qual passaram a ter outros interesses. A família do $A 1$, ainda reside toda na propriedade, porém os filhos se dedicam a outras atividades, somente o agricultor cuida da horta. Na A2, os filhos foram morar em outros espaços, ficando na propriedade somente o casal para realizar todos os trabalhos.

A falta de mão de obra para os trabalhos nos cultivos da horta levou os agricultores a utilizar diferentes estratégias e técnicas para trabalhar a terra. De 1980-1990, período em que os filhos auxiliavam, os canteiros eram feitos com a utilização de cavalo e arado, posteriormente ao ano de 1990 o trator com tobata. Nesses dois períodos é a enxada que dá forma aos canteiros, a qual também foi aposentada com a chegada do trator com canteiradeira, anos 2000, o qual já deixa os canteiros prontos (Figura 05). 
Figura 05 - Canteiros preparados pelo trator com canteiradeira

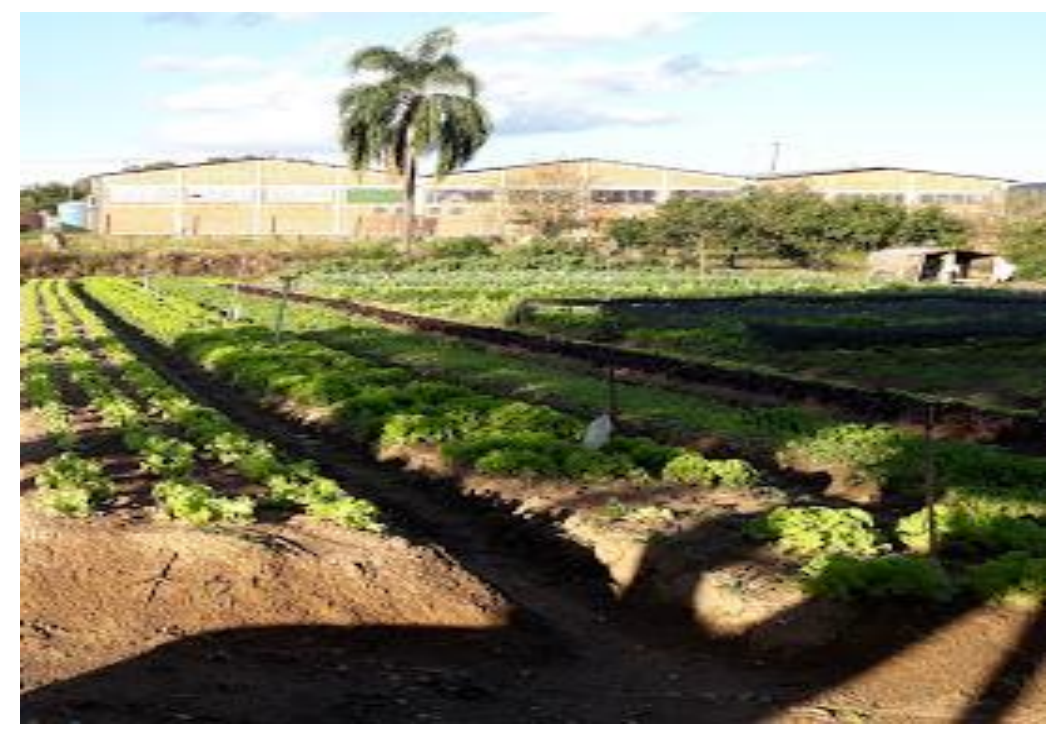

Fonte: Autores (2019).

A técnica utilizada para a irrigação dos canteiros também se alterou, 0 processo artesanal com baldes passou à irrigação por aspersão. Todas essas mudanças facilitaram a vida dos agricultores, permitindo que os mesmos mantenham as propriedades e o cultivo. Toda a água utilizada é proveniente de pontos de nascentes das propriedades.

Os agricultores relatam que o trabalho na horta é intenso, a mesma exige cuidados diários, ocupa todos os dias, prejudicando a disponibilidade de tempo para a realização de outras atividades assim como o lazer. Relatam que se sentem reféns, já que não podem se ausentar.

A nossa produção é praticamente toda artesanal, não temos funcionários e nem esses maquinários de última geração que são controlados pelo celular, por esse motivo não posso ficar muito tempo longe, e nem sair no verão período do ano em que a plantação exige mais cuidados devido a irrigação para umedecer o ambiente ao redor da planta, o que tem que ser feito de cinco a seis vezes no dia quando está muito quente. No inverno já é diferente, o maior cuidado é com as ervas daninhas, eu as arranco e deixo no canteiro mesmo, para virarem adubo (A1, Diário de Campo, 2019).

Os agricultores revelam que adoram o contato com a natureza, destacando que o dinheiro é importante, mas o que apreciam é estar na horta, plantando, colhendo e interagindo com os seus clientes, muitos deles frequentam a horta a mais de 30 anos. Tudo que é produzido sequencialmente é comercializado.

No que se refere aos retornos financeiros a horta é viável, ainda que os agricultores não relatem os valores adquiridos mensalmente, salientam que não realizariam outra atividade, tudo que conseguiram adquirir foi com o trabalho na 
horta e a comercialização das verduras/legumes. Estima-se, que a renda de cada família seja em torno $R \$ 4.000,00$ reais mensais, considerando a estrutura do local, a quantidade de clientes (pessoas físicas e estabelecimentos comercias) fixos, 0 tamanho da área plantada, exigência de pouca mão-de-obra e a satisfação dos agricultores ao desenvolver essa atividade.

Outros fatores observados e que reduz as despesas dessas famílias é que os consumidores vão até as propriedades pesquisadas para comprar seus produtos, a água utilizada para irrigação das hortaliças é proveniente de nascente existente nas propriedades, necessitando apenas de cuidados para a manutenção de sua qualidade. Destacam existir grande procura pelos produtos cultivados e que se tivessem auxilio dos filhos, poderiam ampliar a área de cultivo já que o mercado possui potencialidade para absorver maior produção.

Contudo, o maior limite está na falta de sucessores para as propriedades, os filhos não quererem se inserir na agricultura, se envolveram em demais atividades profissionais, a relação com a terra não é a mesma que os pais possuem. Diante destas circunstâncias, as áreas cultivadas vêm diminuindo, a relação que os pais possuem com a terra é histórica, cultural e muitas vezes até emocional, um espaço de vivência, que representa uma identidade, uma tradição intergeracional.

Porém, Goes et al (2018), ressaltam que a valorização do solo urbano é cada vez mais crescente e cada espaço é disputado por inúmeros atores sociais, e a pressão para tornar áreas rurais (periurbanas) em urbanas é muito grande, por conta dos interesses públicos em aumentar a área de arrecadação de impostos e estar associado ao desenvolvimento, e também os interesses privados em tornar esse espaço em mercadoria, criando loteamentos e condomínios residenciais. Uma possibilidade que pode 'perseguir' as famílias pesquisadas A1 e A2 pode ser justamente essa; a especulação imobiliária.

Ao longo dos anos ambos agricultores venderam partes das propriedades, atualmente as mesmas possuem em média 50\% da área inicial. Não cogitam a possibilidade de abandonar o cultivo, mas sim reduzir as áreas cultivadas, que atualmente estão em torno de um hectare.

\section{As percepções dos consumidores}

A vida do campo está presente nas lembranças e memórias de muitos moradores das cidades. Estes sujeitos, em sua maior parte, saíram das áreas rurais pela falta de perspectivas, migraram para áreas urbanas em busca de melhores de 
condições de vida. Esses migrantes dotados de uma identidade territorial, possuem o sentimento de pertencimento ao espaço rural e passam a buscar produtos locais que representem essa identidade.

Nesse contexto, o mercado começa a atribuir valor aos bens simbólicos, os quais se tornam um novo nicho de mercado. Cada vez mais, a busca pela sustentabilidade urbana baseada na maximização da eficiência do uso de terra, da água e redução nas descargas de lixo são critérios considerados pelos consumidores na hora da tomada de decisão pelas fontes dos produtos consumidos, (MELO, 2016).

Tais consumidores são encontrados também no município de Santa Maria, RS. Como exemplo cita-se a clientela das hortaliças das áreas pesquisadas, que "além de buscarem um alimento mais saudável, que preserve o meio ambiente, ainda vão atrás de experiências que nutram suas lembranças, alimento pro corpo e a alma" (A1, Diário de Campo, 2018). As pessoas que se dirigem aos espaços das hortas, podem entrar nos canteiros, escolher e colher os produtos que desejam levar, como pode-se observar na Figura 06.

O espaço da horta não é somente frequentado pela população urbana que tem origens rurais e carrega consigo a saudade do trabalhar a terra para o cultivo do seu próprio alimento, mas, também por uma parcela da população nascida no urbano. Esse público busca uma alimentação diferenciada, alimentos saudáveis. No mais, a experiência palpável da colheita do que vai consumir é muito atrativa aos consumidores, principalmente os mais jovens. Pais levam seus filhos para aprenderem na prática como se desenvolvem as hortaliças, possibilitando vivências e experienciais múltiplas, estabelecendo uma relação mais direta com a natureza.

Figura 06 - Espaço de colheita na horta

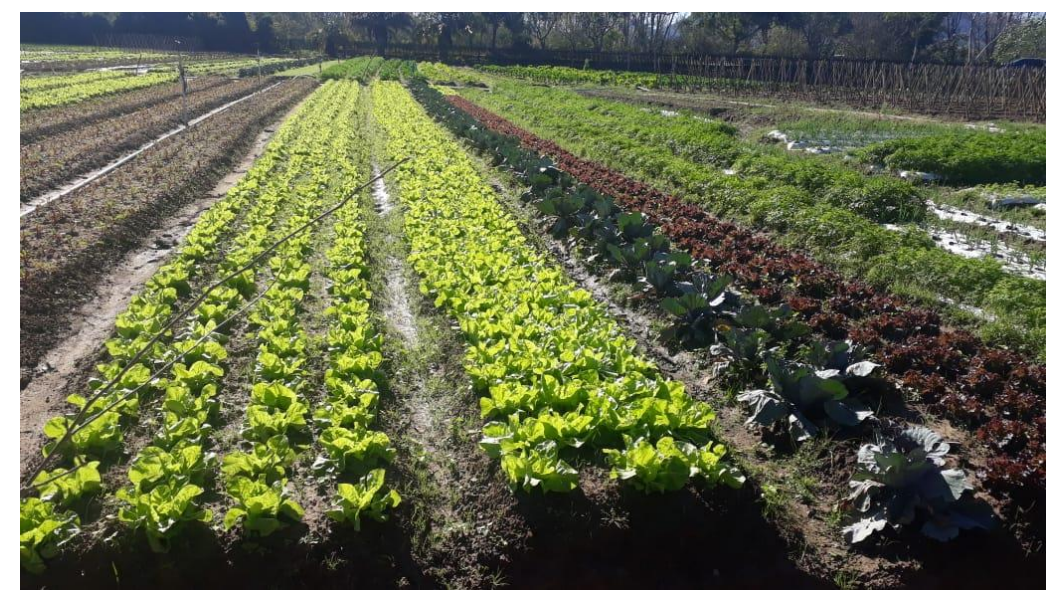

Fonte: Autores, (2019). 
Cada vez mais é indispensável pensar na produção alternativa de alimentos orgânicos e a manutenção ambiental. Bem como da necessidade da organização das cidades dentro de um sistema de sustentabilidade, que englobe aspectos sociais, econômicos, ambientais, culturais, espaciais e institucionais (MELO, 2016). O Governo Federal, através do Ministério da agricultura, Pecuária e Abastecimento, quer estimular o avanço das discussões do projeto de lei que tramita na Câmara (PL 906/2015) e que institui a Política Nacional de Agricultura Urbana, (BRASIL, 2019), isso significa que as áreas de agricultura urbana e periurbana podem ser fortalecidas, caso essa proposta se efetive no âmbito do território nacional.

\section{Considerações Finais}

Diferentes atividades relacionadas com a prática da agricultura vêm se desenvolvendo em distintos espaços urbanos/periurbanos, gerando renda e exigindo pouca mão-de-obra. Estas atividades têm modificado as paisagens urbanas com da presença de cultivos que outrora se materializavam no espaço rural. As áreas pesquisadas se apresentam enquanto substrato espacial material agrário dentro da área urbana da cidade de Santa Maria-RS. Nestes espaços há uma diversidade de produtos que são cultivados e comercializados.

A partir do cultivo e a comercialização das hortícolas as famílias entrevistadas vêm conseguindo se manter ao longo dos anos. Apesar de não indicar valores, o retorno financeiro é considerado positivo, visto que o acesso ao mercado é amplo, os produtos são comercializados em diversos pontos de feiras da cidade, mercados assim como nas propriedades. Outro fator que aponta para isso é o tempo em que a atividade é desenvolvida pelas famílias.

Algumas famílias levam os filhos para colher os produtos, assim estes passam a ter contato com o espaço de produção dos alimentos e compreendem a importância desta atividade na disponibilidade de alimentos para a população. O que demonstra que o local do cultivo e comercialização também é um espaço de reprodução social, de convívio, de relações sociais e culturais, fortemente marcado pela dimensão simbólica.

No mais a consolidação das feiras livres e agroecológicas fazem parte da realidade e da identidade do município de Santa Maria, RS. A ampliação destas tem possibilitado o crescimento do cultivo de hortícolas em áreas urbanas e periurbanas. 
A produção hortícola é considerada uma fonte de entrada de renda para as famílias, visto que semanalmente os produtos são comercializados nas feiras, mercados e propriedades. Por fim, salienta-se que a falta de sucessores para dar continuidade a atividade se configura como a maior limite. Ainda que exista uma potencialidade de crescimento pela crescente demanda de alimentos de qualidade, a manutenção e permanência destes está diretamente relacionado a disponibilidade de mão de obra.

\section{REFERÊNCIAS}

ADAM, M. G. Definitions and boundaries of the periurban interface - patterns in the patchwork. Paper presented at IBSRAM International Workshop on Urban and Peri Urban Agriculture, Accra, Aug., 1999.

AQUINO, Adriana M. de; ASSIS, Renato L. de. Agricultura orgânica em áreas urbanas e periurbanas com base na agroecologia. Revista Ambiente \& Sociedade. Campinas, SP: v. X. no 1, p. 137-150. Jan-jun. 2007.

BOLFE S. A. Expansão urbana de Santa Maria-RS: uma avaliação da adequabilidade do uso do solo, São Paulo, Dissertação (Mestrado em Geografia Humana), Universidade de São Paulo, 1997.

BRASIL, Ministério da Agricultura, Pecuária e Abastecimento. Hortas ganham espaço nas cidades e se tornam alternativa de acesso à comida saudável. Brasília-DF, 2019. Disponível em: <http://www.agricultura.gov.br/noticias/hortas-ganham-espaco-nas-cidadese-se-tornam-alternativa-de-acesso-a-comida-saudavel>. Acesso em: 10 de maio de 2019.

CORRÊA, R. L. Estudos sobre a rede urbana. Bertrand Brasil, 2006.

FAO. Issues in urban agriculture - Studies suggest that up to two-thirds of city and periurban households are involve in farming. 1999. Disponível em: s http://www.fao.org/ag/magazine/9901ap2.htm>. Acesso em: 05 de jun. de 2019.

INSTITUTO DE PLANEJAMENTO DE SANTA MARIA - IPLAN. Mapa do bairros. Disponível em: < http://iplan.santamaria.rs.gov.br/site/home/pagina/id/147>. Acesso em: 04 de ag. de 2019.

GOIS, Rodrigo C.; ALVES, Flamarion D.; BRANQUINHO, Evânio dos S. Agricultura urbana e periurbana e os conflitos da especulação imobiliária em Alfenas-MG. Revista de Geografia, Rio Claro, v. 43, n. 1, Especial - VI Encontro REA, p. 107-118, jan./abr. 2018.

MELO, L. P. Os benefícios da agricultura urbana e periurbana para a sustentabilidade da cidade de Macapá-AP. In: PLURIS. $7^{\circ}$ Congresso Luso Brasileiro para o Planejamento Urbano, Regional, Integrado e Sustentável - contrastes, condições e complexidades. Maceió-Al: 05 a 07 de outubro de 2016. Disponível em: $<$ http://www.fau.ufal.br/evento/pluris2016/files/Tema\%204\%20\%20Planejamento\%20Regional\%20e\%20Urbano/Paper1342.pdf>.

MOUGEOT, L .J. A. Urban agriculture: definition, presence, potentials and risks. In: BAKKER, N.; DUBBELING, M.; GÜNDEL, S.; SABEL-KOSCHELLA, U.; ZEEUW, H. (Ed.). Growing cities, growing food: urban agriculture on the policy agenda. Feldafing: Deutsche Sitffung für Internationale Entwicklung, 2000, p.1-42. 
OLIVEIRA, Igor Martins de. Tradições rurais em vidas urbanas: a agricultura urbana no bairro vila Anália, Montes Claros/MG. 87f. TCC (Trabalho de Conclusão de Curso, Graduação em Geografia). Universidade Estadual de Montes Claros-Unimontes, Montes Claros, 2011.

PEREIRA, A. S. Análise das tendências de aplicação do conceito de periurbano. Terr@Plural, Ponta Grossa, v.7, n.2, p. 287-304, jul/dez. 2013.

PNUD. Urban agriculture: food, Jobs, and sustainable cities. 1996. Disponível em: $<$ http://www.jacsmit.com/book.html> . Acesso em 08/07/2018.

SANTOS, M.; SILVEIRA, M. L. O Brasil: território e sociedade no início do século XXI. 8 edição, Rio de Janeiro: Record, 2005.

SANTOS, Milton. Metamorfoses do Espaço Habitado: Fundamentos Teóricos e Metodológicos da Geografia; em colaboração com Denise Elias. - "6.ed - São Paulo: Editora da Universidade de São Paulo, 2008.

SANTOS, Milton. A Natureza do Espaço: Técnica e Tempo, Razão e Emoção/Milton Santos. - 4. ed. 2. reimpr. - São Paulo: Editora da Universidade de São Paulo, 2006.

SANTOS, Milton. Pensando o espaço do homem. São Paulo. Ed. HUCITEC, 4 edição, 1997.

SANTANDREU, Alain; LOVO, Ivana. Panorama da agricultura urbana e periurbana no Brasil e diretrizes políticas para sua promoção: identificação e caracterização de iniciativas de agricultura urbana e periurbana em regiões metropolitanas brasileiras, mimeo, 2007.

SPOSITO, M.E.B. Cidades Médias: Reestruturação das Cidades e Reestruturação Urbana. In: Cidades Médias: espaços em transição. 1oed. São Paulo: Expressão Popular, 2007. p. 233-253.

SOUZA, Marcelo Lopes de. Os conceitos fundamentais da pesquisa sócio-espacial. 1 ed. Rio de Janeiro: Bertrand Brasil, 2013.

VILLAÇA, Flávio. Espaço Intra-Urbano no Brasil. São Paulo: Studio Nobel: FAPESP: Lincoln Institute, 1998.

VILELA, Sergio L. de O.; MORAES, Maria D. C. de. Agricultura urbana e periurbana: limites e possibilidades de constituição de um sistema agroalimentar localizado no município de Teresina - PI. Revista Economica do Nordeste. NE, Fortaleza, v. 46, n. 1, p. 97-114, jan.-mar., 2015.

WANDERLEY, M. N. B. A valorização da agricultura familiar e a reivindicação da ruralidade no Brasil. Desenvolvimento e Meio ambiente. Curitiba, v. 2, p. 29-37, 2000.

\section{NOTAS DE AUTOR}

\section{CONTRIBUIÇÃO DE AUTORIA}

Janete Webler Cancelier - Concepção do manuscrito, coleta de dados, análise de dados. Elaboração do manuscrito, revisão e aprovação da versão final do trabalho.

Cesar De David - Elaboração do manuscrito. Participação ativa da discussão dos resultados; Revisão e aprovação da versão final do trabalho. 
Janete Facco - Elaboração do manuscrito. Participação ativa da discussão dos resultados; Revisão da versão final do trabalho.

\section{FINANCIAMENTO}

Não se aplica.

\section{CONSENTIMENTO DE USO DE IMAGEM}

Não se aplica.

\section{APROVAÇÃO DE COMITÊ DE ÉTICA EM PESQUISA}

Não se aplica.

\section{CONFLITO DE INTERESSES}

Não se aplica.

\section{LICENÇA DE USO}

Este artigo está licenciado sob a Licença Creative Commons CC-BY. Com essa licença você pode compartilhar, adaptar, criar para qualquer fim, desde que atribua a autoria da obra.

\section{HISTÓRICO}

Recebido em: 17-11-2019

Aprovado em: 20-05-2020 